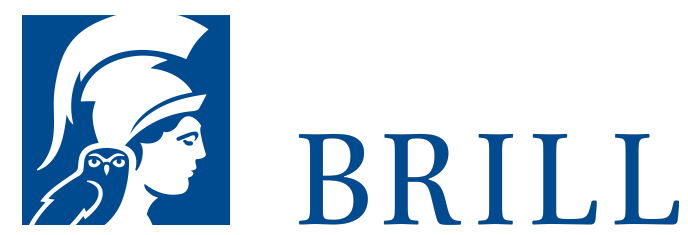

\title{
Friedrich Fröbel und seine Spielpädagogik
}

\section{Eine Einführung}

Authors: Michael Winkler and Ulf Sauerbrey

Friedrich Fröbel ist als Entdecker des ersten Kindergartens und Entwickler von Spielgaben zwar durchaus bekannt. Wie seine Spielpädagogik jedoch als System beschaffen ist, was in dieser die >Pflege des kindlichen Spiel- und Beschäftigungstriebes< bedeutet und wie Fröbels elementardidaktische Ideen im Laufe seines Lebens überhaupt entstanden sind, ist außerhalb der Fröbelforschung bislang kaum bekannt. Der Band richtet sich an Interessierte aus Wissenschaft und Praxis, besonders jedoch an Studierende der pädagogischen Fächer und Disziplinen. Sein Ziel ist die Bereitstellung grundlegender Kenntnisse über pädagogische Zäsuren in Fröbels Biografie, die seine Spielpädagogik beeinflussten. Im Zentrum steht die Beschreibung der Fröbelschen Spielpädagogik als Ideengerüst und Handlungskonzept. Ergänzt wird dieser historische Zugang um einen gegenwartsbezogenen Brückenschlag, der die bislang ungebrochene Aktualität der Spielpädagogik Fröbels exemplarisch aufzeigt.

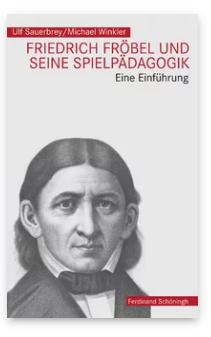

Pages: 215

Seiten

Language:

German

Subjects:

General,

Education

Publisher: Brill |

Schöningh

E-Book (PDF)

Released online:

13 Dec 2017

ISBN: $978-3^{-}$

657-78441-7

List price

Paperback

Publication date:

o1 Dec 2017

ISBN: $978-3^{-}$

506-78441-4

List price 
Ulf Sauerbrey ist Privatdozent am Lehrstuhl für Allgemeine Pädagogik und Theorie der Sozialpädagogik an der FriedrichSchiller-Universität Jena.

Michael Winkler ist seit 1992 Professor für Allgemeine Pädagogik und Theorie der Sozialpädagogik an der FriedrichSchiller-Universität in Jena. 2008 gründete er gemeinsam mit Ralf Koerrenz das international ausgerichtete Institut für Bildung und Kultur.

For more information see brill.com

Order information: Order online at brill.com +44330 3330049 | customerservices@brill.com Submission information: brill.com/authors

Titles published by Brill | Fink, Brill | mentis or Brill | Schöningh: +49(o)71 5413279216 | brill@brocom.de 